\title{
Effects of remifentanil-propofol combined with dexmedetomidine on cognitive dysfunction in elder patients after ureteroscopic holmium laser lithotripsy: A double-blind randomized controlled trial
}

Fangjun Wang ( $\square$ wfjlxy006@nsmc.edu.cn )

North Sichuan Medical University

Dan Xie

Affiliated Hospital of North Sichuan Medical College

Hongchun Xu

Affiliated Hospital of North Sichuan Medical College

Qin Ye

Affiliated Hospital of North Sichuan Medical College

Le Wu

Affiliated Hospital of North Sichuan Medical College

Xiaopei Gao

Affiliated Hospital of North Sichuan Medical College

Research

Keywords: dexmedetomidine, remifentanil, propofol, cognitive dysfunction

Posted Date: July 28th, 2020

DOI: https://doi.org/10.21203/rs.3.rs-19913/v1

License: (c) (i) This work is licensed under a Creative Commons Attribution 4.0 International License.

Read Full License 


\section{Abstract}

\section{BACKGROUND}

Clinical study indicated that infusion of dexmedetomidine without loading dose intraoperative provided smooth and haemodynamically stable emergence, and improved quality of recovery with fewer postoperative side effects and analgesic requirements 9 . The objective is to determine remifentanilpropofol combined with dexmedetomidine during general anesthesia would decrease the incidence and severity of postoperative emergence agitation, anxiety and depression, and without effect on the cognitive dysfunction in elder patients.

\section{METHODS}

120 elder patients scheduled for ureteroscopic holmium laser lithotripsy were randomly allocated to PR group administered the normal saline, and PRD group administered dexmedetomidine $0.4 \mu \mathrm{g} . \mathrm{Kg}-1$.h -1 intravenously after induction of anesthesia, and stopped 30 minutes before the end of surgery. The primary outcome was the scores of richmond agitation sedation, mini mental state examination, statetrait anxiety inventory, zung self-Rating depression scale, and the arabic numeral memory. The secondary outcome was the duration of surgery, and time to spontaneous respiration, recovery and extubation.

\section{RESULTS}

The dosage of propofol and remifentanil decreased more significantly in PRD group $(P<0.001)$. The RASS scores in the PRD group was significantly lower than in PR group at t 1-3 ( $P<0.001)$. The MMSE scores were lower at T 1 - 2 in two groups $(P<0.001)$. Compared to PR group, the ZSDS scores and STAI scores at $T 1-2$ were lower in PRD group $(P<0.005)$. The recalled arabic numbers were lower at $T 2$ in PR group $(P<0.001)$.

\section{CONCLUSION}

Dexmedetomidine administration could reduce both the dosage of remifentanil and propofol during surgery, and the incidence and severity of postoperative emergence agitation, anxiety and depression in elderly patients.

Trial registration

the Chinese Clinical Trial Registry, ChiCTR1900021254, Registered 3 February 2019, http://www.chictr.org.cn/ChiCTR1900021254.

\section{Introduction}

Postoperative cognitive dysfunction (POCD) is a common complication after surgery that adversely affects the social independence, quality of life, and mortality of patients ${ }^{1}$. Approximately $12 \%$ of 
apparently previously cognitively well patients undergoing anaesthesia and noncardiac surgery will develop symptoms of cognitive dysfunction after their procedure ${ }^{2}$. In particular, the incidence of POCD is much higher for elderly Surgical patients ${ }^{3}$. The Risk factors including preoperative impairment in neurocognitive function, old age, metabolic disturbances, duration/type of surgery, hypoxemia, use of certain anesthetics, and pain are implicated in contributing to $P O C D^{4}$. As yet no effective treatment for $P O C D$, the prevention of occurrence or reduction the incidence of POCD is more important.

The incidence of POCD was significantly higher in elderly patients undergoing laparoscopic cholecystectomy anaesthetized with sevoflurane or isoflurane compared to propofol ${ }^{5}$. Ekmekci P et al reported that Propofol-remifentanil is better than meperidine-midazolam concerning cognitive function in sedation for colonoscopy ${ }^{6}$. Propofol-remifentanil allows earlier cognitive recovery compared to Propofoldexmedetomidine ${ }^{7}$. These results showed that maybe Propofol-remifentanil is a good choice of anesthesia for elderly Surgical patients.

However, both propofol and remifentanil are rapid onset, short duration, and rapid revival, it leads to early postoperative catheter-related bladder discomfort( CRBD) and earlier demand for postoperative analgesics ${ }^{7,8}$. The clinical study indicated that infusion of dexmedetomidine without loading dose intraoperative provided smooth and haemodynamically stable emergence, and improved quality of

recovery with fewer postoperative side effects and analgesic requirements after nasal surgery ${ }^{9}$. Thus, we postulated that intraoperative infusion of dexmedetomidine without loading dose would decrease the incidence and severity of early postoperative CRBD, and have little effect on the cognitive dysfunction in elder patients undergoing ureteroscopic holmium laser lithotripsy anaesthetized with Propofolremifentanil. Therefore, we designed this study to test the hypothesis that remifentanil-propofol combined with or without dexmedetomidine would have the same effects on postoperative cognitive function in elderly patients after ureteroscopic holmium laser lithotripsy.

\section{Methods}

Following the approval by the Ethics Committee of the affiliated hospital of north sichuan medical college, we obtained the written informed consent from all the participants for this randomized prospective clinical trial conducted at the affiliated hospital of north sichuan medical college, on patients with the upper urinary tract calculi. This prospective, double-blind, randomized controlled study was registered at the Chinese Clinical Trial Registry (http://www.chictr.org.cn/; Registration number》 ChiCTR1900021254).

One hundred and twenty adult ASA I-II patients between 60 and 75 years of age undergoing ureteroscopic holmium laser lithotripsy were enrolled in the study between February 2019 and September 2019. Patients scheduled for elective ureteroscopic holmium laser lithotripsy under general anesthesia, and fasted for $12 \mathrm{~h}$ for solid food, and $6 \mathrm{~h}$ for clear liquids before the study were included in the study. The exclusion criteria were as follows: adverses response to propofol, remifentanil or dexmedetomidine, presence of cardiovascular disease, endocrine disease, liver or kidney dysfunctions, recent smoking, 
history of chronic use of alcohol, sedatives, opioid, cognitive dysfunction or paracenesthesia and change of surgical.

Patients were divided randomly into two groups, using sealed envelopes indicating the allocation, to receive intravenous dexmedetomidine $0.4 \mu \mathrm{g} \cdot \mathrm{Kg}^{-1} \cdot \mathrm{h}^{-1}$ (PRD group, $n=60$ ) or equal volume of normal saline (PR group, $n=60$ ) after general anesthesia induction. Randomization was performed by an anesthesiologist who was not responsible for Surgical anesthesia of the patients or data collection. The study drugs were administered by an anesthetic nurse while the anesthesiologist responsible for the patient did not know what they were.

Preoperative visits and communications with patients and their relatives were conducted the day before surgery. The patients were familiar with the questionnaires which included mini-mental state examination (MMSE), State-Trait Anxiety Inventory (STAI), Zung Self-Rating Depression Scale (ZSDS), and remembered five random arabic numbers.

Patients enrolled in the study were premedicated with an intramuscular injection of atropine $(0.5 \mathrm{mg}), 30$ minutes before the induction of anesthesia. When the patients arrived in the operating $\operatorname{room}\left(\mathrm{T}_{0}\right)$, recalled the arabic numbers(RAM) which remembered the day before surgery and Counted the correct number, then the Mini Mental State Examination (MMSE), State-Trait Anxiety Inventory (STAI), and Zung SelfRating Depression Scale (ZSDS) were applied. Routine monitoring included electrocardiography, noninvasive blood pressure(systolic blood pressure, mean arterial pressure and diastolic blood pressure), heart rate, respiratory rate, pulse oximetry, end-tidal $\mathrm{CO} 2$, the bispectral index and temperature was started.

Patients were induced with intravenous propofol $2 \mathrm{mg} / \mathrm{kg}$, remifentanil $2 \mu \mathrm{g} / \mathrm{kg}$, Cisatracurium $0.15 \mathrm{mg} / \mathrm{kg}$. Following the endotracheal tube was inserted, controlled mechanical ventilation were adjusted to maintain an end- tidal carbon dioxide concentration of 40 to $45 \mathrm{mmHg}$. Immediately after induction of anesthesia, the dexmedetomidine $0.4 \mu \mathrm{g} \cdot \mathrm{Kg}^{-1} \cdot \mathrm{h}^{-1}$ was infused intravenously in dexmedetomidine group, while equal volume of normal saline was administrated in control group. Anesthesia was maintained with plasma target concentration of propofol $2 \sim 3 \mu \mathrm{g} / \mathrm{ml}$, remifentanil $4 \sim 6$ $\mathrm{ng} / \mathrm{ml}$, and the value of the bispectral index was maintained between 40 and 60 during surgery.

Cisatracurium was given intraoperatively if required. The administration of Cisatracurium, dexmedetomidine or placebo, and propofol-remifentanil were stoped 45,30, and 5 minutes before the end of surgery respectively. Bradycardia (heart rate below 50 beats $/ \mathrm{min}$ ) and hypertension (SBP below 90 $\mathrm{mmHg}$ ) were treated with atropine $(0.5 \mathrm{mg})$ and ephedrine $(5 \mathrm{mg})$ intravenously, respectively.

The patients were extubated after spontaneous respiration (tidal volume $>6 \mathrm{ml} / \mathrm{kg}$, respiratory rate $>$ $13 / \mathrm{min}$ ), a train-of-four (TOF) ratio $\geq 0.9, \mathrm{SpO}_{2}>90 \%$ under air inspiration, and $\mathrm{BIS}>80$. The duration of surgery, and time to spontaneous respiration, recovery and extubation (time from stopping administration of propofol-remifentanil to spontaneous respiration, recovery and extubation respectively) were recorded. Patients were transferred to the post-anesthesia care unit(PACU) after extubation . $\mathrm{O}_{2}$ was applied at $5 \mathrm{~L}$ 
$\min ^{-1}$ via a nasal catheter. The PACU emergence agitation score was evaluated10 minutes $\left(\mathrm{t}_{1}\right), 20$ minutes $\left(t_{2}\right), 30$ minutes $\left(t_{3}\right)$ and 60 minutes $\left(t_{4}\right)$ after extubation by an anesthetic nurse blinded to the study using the Ramsay sedation scale (RASS: +4 , combative; +3 , very agitated; +2 , agitated; +1 , restless; 0 , alert and calm; -1 , drowsy; -2 , light sedation; -3 , moderate sedation; -4 , deep sedation; -5 , unarousable) ${ }^{10}$. Emergence agitation(EA) was defined as any RASS score $\geq+2$, with severe EA defined as RASS $\geq+3$. When the modified Aldrete score $>9$, the patients were transferred to the surgical ward ${ }^{11}$. The duration of stay in the PACU was recorded.

The MMSE, STAI,ZSDS, and RAM were applied at $3 h\left(T_{1}\right), 6 h\left(T_{2}\right), 24 h\left(T_{3}\right), 48 h\left(T_{4}\right)$ and $72 \mathrm{~h}\left(\mathrm{~T}_{5}\right)$ postoperatively.

\section{Statistical analysis}

A previous study ${ }^{12}$ showed that the mean $\pm S D$ value of MMSE scores evaluated at 6 h postoperatively in patients anesthetized with intravenous propofol-remifentanil was $24.3 \pm 2.3$, and POCD was considered according to the criteria of MMSE score reductions of $\geq 1 \pm$ standard deviation. We calculated that a sample size of 62 patients was required in each group at a power of $90 \%$, with a two-sided significance level of 0.05 by an independent $t$-test. To account for a $10 \%$ dropout rate, we included 68 patients in each group. We thus planned to enroll 136 subjects in this study.

Statistical analyses were performed using SPSS22.0 program. Results are expressed as the mean \pm standard deviation (SD). One-way analysis of variance (ANOVA) was used to compare mean differences between groups for demographic data (age and weight), time of operation, time to spontaneous respiration, time to recovery and time to extubation, and dosage of propofol and remifentanil administered. Two-way ANOVA, followed by post hoc tests, was used to analyze the scores of MMSE, STAI, ZSDS, and RAM. The sex ratio, ASA physical status, levels of education and scores of RASS were analysed using the $X^{2}$ or Fisher exact tests. $P<0.05$ was considered statistically significant.

\section{Results}

One hundred and thirty-four patients were screened for eligibility, four patients with hypertension were excluded, three patients declined to participate and two patients were Cancelled the surgical procedure. 125 patients were subsequently allocated to two groups. Surgical plan changed in 5 patients during operation. A total of one hundred and twenty patients completed the study and were analysed (Fig. 1). There was no differences between groups regarding demographics (Table 1). The duration of surgery, time to spontaneous respiration and the length of stay in the PACU were similar between groups. The dosage of propofol or remifentanil was significantly lower in PRD group compared with PR group $(p<$ $0.001)$. The time to recovery and tracheal extubation time were delayed greater in PRD group $(p<0.001)$ (Table 2). 
The Richmond Agitation Sedation scores are shown in table 3.The RASS scores in the PRD group was significantly lower than in PR group at $\mathrm{t}_{1}, \mathrm{t}_{2}, \mathrm{t}_{3}(P<0.001)$. The incidence of EA in the PRD group was significantly lower than in PR group at $\mathrm{t}_{1}(10.0 \%[6 / 54]$ vs $40.0 \%[24 / 36]), \mathrm{t}_{2}(3.3 \%[2 / 58]$ vs $40.0 \%[24 / 36])$, $t_{3}(0.0 \%[0 / 60]$ vs $23.3 \%[14 / 46])$. The Mini Mental State Examination scores are shown in table 4 . The MMSE scores were lower at $T_{1}$ and $T_{2}$ compared to $T_{0}$ in two groups. But the MMSE scores were similar between the two groups at $T_{0}, T_{1}, T_{2}, T_{3}, T_{4}$, and $T_{5}$. The Zung Self-Rating Depression Scale scores are shown in table 5. The ZSDS scores in PR group were higher compared to PRD group at $T_{1}$ and $T_{2}$ $(P<0.001)$, and the ZSDS scores were similar between the two groups at $T_{0}, T_{3}, T_{4}$, and $T_{5}$. The ZSDS scores were higher at $T_{1}$ and $T_{2}$ compared to $T_{0}$ in PR group $(P<0.001)$, and there were no differences in ZSDS scores at $T_{0}, T_{1}, T_{2}, T_{3}, T_{4}$, and $T_{5}$ in PRD groups $(P=0.359)$. The State-Trait Anxiety Inventory scores are shown in table 6 . The STAI scores were higher at $T_{1}$ and $T_{2}$ compared to $T_{0}$ in PR group, and the STAI scores were higher at $T_{1}$ compared to $T_{0}$ in PRD group. The STAI scores at $T_{1}$ and $T_{2}$ were lower in PRD group compared to PR group $(P<0.005)$. The recalled arabic numbers are shown in table 7 . The recalled arabic numbers were lower at $T_{1}$ and $T_{2}$ in PR group and at $T_{1}$ in PRD group compared to $T_{0}$ $(P<0.001)$. The recalled arabic numbers were lower at $\mathrm{T}_{2}$ in $\mathrm{PR}$ group compared to PRD group $(P<0.001)$.

\section{Discussion}

The results of this clinical trial showed that a combination of intravenous dexmedetomidine $0.4 \mu \mathrm{g} \cdot \mathrm{Kg}^{-1} \cdot \mathrm{h}^{-}$

1 resulted in lower incidence and severity of postoperative emergence agitation in elder patients undergoing ureteroscopic holmium laser lithotripsy. Intravenous dexmedetomidine reduced the use of remifentanil and propofol during operation. Although there was no difference between groups in influence on postoperative cognitive dysfunction, the patients anaesthetized with remifentanil-propofol combined with or without dexmedetomidine had transient postoperative cognitive dysfunction. The duration of anxious and depression after operation were longer in the patients treated without intravenous dexmedetomidine.

Postoperative cognitive dysfunction (POCD) is one of the most common postoperative complications in elderly patients and is associated with an increased risk of death in the first year after surgery ${ }^{13}$. Advancing age, multiple surgeries, duration of anesthesia and acute postoperative pain have been implicated as the risk factors for $\mathrm{POCD}^{14,15}$. The older surgical patients have probable cognitive impairment preoperatively, and the impairment is associated with development of delirium postoperatively ${ }^{16}$. We previously found that the incidence of postoperative cognitive dysfunction was higher in elderly patients with inhalational anaesthesia compared to total intravenous anaesthesia ${ }^{17}$. Both anesthetic and pain management strategies do appear to influence the risk of cognitive dysfunction after elective joint arthroplasty, and perioperative pain may be a risk factor for postoperative delirium ${ }^{18-}$ ${ }^{20}$. In the present study, we selected patients undergoing ureteroscopic holmium laser lithotripsy with minor acute postoperative pain, thus avoiding the effects of postoperative pain and postoperative analgesic drugs on POCD in elderly patients. Our study showed that the MMSE scores were decreased 
significantly 3th hour after surgery, and restored to pre-anesthesia level 24th hour after surgery in two groups. This Suggests that postoperative cognitive dysfunction was temporary during TIVA with remifentanil and propofol given by $\mathrm{TCl}$ with or without dexmedetomidine in elderly patients undergoing ureteroscopic holmium laser lithotripsy. In contrast, Ilvan G et al. ${ }^{19}$ reported that the TIVA method did not affect postoperative early cognitive functions in either old or young patients who underwent lumbar disk surgery. The time to apply the MMSE postoperatively might be responsible for the differences. Because they applied the MMSE 24h after surgery and found no one experienced POCD, and the MMSE scores were decreased significantly 3th hour and restored 24th hour after surgery in our study. Therefore, their results could not demonstrate that no transient cognitive dysfunction was occurred within 24 hours postoperatively. Our results were consistent with previous studies that propofol might cause POCD ${ }^{21,22} \square$ and different with the results reported by Zhang $D$ et al. ${ }^{23}$ that propofol might be able to inhibit the inflammatory response in central nervous system and improve POCD. This indicated that prolonged propofol-based general anesthesia may have an effect on the central nerve system, and short-term infusion propofol during TIVA would yield a minimal influence on postoperative cognitive function.

Dexmedetomidine is a new $\mathrm{a}_{2}$ adrenergic receptor agonist with a short half-life (about two hours), and it has a dose-dependent sedative and analgesic effects and no negative effects on respiration ${ }^{24}$. A metaanalysis done by Tan JA et al. found that dexmedetomidine could induce sedation without increasing delirium ${ }^{25}$. These findings are compatible with the results of our study that dexmedetomidine has no effects on postoperative cognitive function in elderly patients anaesthetized with remifentanil and propofol. Several studies have demonstrated that dexmedetomidine may benefit cognitive function in elderly patients due to its neuroprotective effect and inhibiting inflammation ${ }^{24,26,27}$. In our study, we didn't detect the Plasma inflammatory factors, and the effect of dexmedetomidine on plasma inflammatory mediators in elderly patients was unclear. Tan JA et al. ${ }^{25}$ reported that the risk of bradycardia was significantly higher when both a loading dose and high maintenance doses $(>0.7$ microg $/ \mathrm{kg} / \mathrm{h}$ ) were used. In the present study, no patients required intervention for bradycardia or hypotension. This may be due to the intraoperative infusion of dexmedetomidine without loading dose and lower maintenance doses $(0.4 \mathrm{microg} / \mathrm{kg} / \mathrm{h}<0.7 \mathrm{microg} / \mathrm{kg} / \mathrm{h})$.

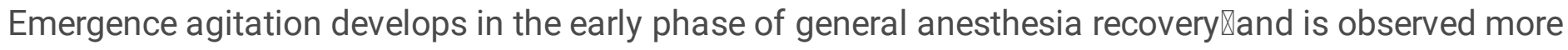
frequently in ENT (ear, nose, and throat) surgical patients ${ }^{28}$. EA is characterized by agitation, confusion, disorientation, and possible violent behavior ${ }^{28,29}$. EA can cause hemorrhage, falling out of the bed, selfextubation, removal of catheters, even injury to the patient or medical staff ${ }^{30}$. The present study describes a higher incidence of EA in PR group compared to PRD group. This indicated that intravenous dexmedetomidine after induction of anaesthesia significantly reduced the incidence and severity of EA postoperatively in elderly patients undergoing TIVA with remifentanil and propofol for ureteroscopic holmium laser lithotripsy. The independent risk factors for EA such as younger age, recent smoking, sevoflurane anesthesia, postoperative pain of NRS $\geq 5$, presence of a tracheal tube, and presence of a urinary catheter were identified ${ }^{28}$. In our study, postoperative catheter-related bladder discomfort(CRBD) 
was more complained by elderly patients in PR group. This suggested that the intraoperative intravenous dexmedetomidine could decrease the incidence and severity of early postoperative CRBD. Our results were consistent with previous studies that intraoperative administration of dexmedetomidine is a safe and effective practice for the prevention of CRBD after lumbar microdiscectomy and can reduce postoperative pain ${ }^{31-33}$. The lower incidence of EA in PRD group in present study may be attributed to the decreased incidence and severity of early postoperative CRBD.

In our study, both the ZSDS scores and the STAI scores were increased at 3th hour and restored 12th hour after operation in PR group. However, only the STAI scores were increased at 3th hour and restored 6th hour postoperatively in PRD group. This indicated that intraoperative infusion of dexmedetomidine could attenuate the severity of postoperative anxiety and depression in elderly patients. Ingrid Rundshagen reported that an anxious, depressed basal mood have been identified as further risk factors for POCD ${ }^{34}$. Then the administrated of dexmedetomidine may benefit to the postoperative cognitive function by decreasing incidence and severity of postoperative anxiety and depression.

There are limitations to our study. We didn't detect the Plasma inflammatory factors in our study. Many studies have reported that the protective effect of dexmedetomidine on cognitive function due to its inhibiting inflammation ${ }^{24-26}$. The patients selected in our study had almost no postoperative pain, so the effects of remifentanil-propofol combined with or without dexmedetomidine on cognitive dysfunction in elder patients with postoperative pain were unclear.

In conclusion, the present study showed that intravenous dexmedetomidine could provide clinically relevant benefits in elderly patients undergoing ureteroscopic holmium laser lithotripsy surgery.

Dexmedetomidine administration could reduce the dosage of remifentanil and propofol during surgery. Although dexmedetomidine had no effect on postoperative cognitive dysfunction, it cloud reduce the incidence and severity of postoperative emergence agitation, anxiety and depression in elderly patients.

\section{Declarations}

Ethics approval and consent to participate: All procedures performed in studies involving human participants were in accordance with the ethical standards of the institutional and/or national research committee and with the 1964 Helsinki declaration and its later amendments or comparable ethical standards. Following the approval by the Ethics Committee of the affiliated hospital of north sichuan medical college, we obtained the written informed consent from all the participants for this randomized prospective clinical trial conducted at the affiliated hospital of north sichuan medical college, on patients with the upper urinary tract calculi.

Consent for publication $\bigotimes$ There was no details, images, or videos relating to an individual person in this manuscript.

Trial registration: The Chinese Clinical Trial Registry, ChiCTR1900021254, Registered 3 February 2019, http://www.chictr.org.cn/ChiCTR1900021254 . 
Availability of data and materials:we presented the study datasets in additional supporting files(PRD-PR study data. XLSX).

Assistance with the study: none.

Financial support and sponsorship: this study was funded by the Foundation of Si'chuan Health Department (17PJ215). The funding body had no influence on the design of the study, collection, analysis, interpretation of data and writing the manuscript.

Conflicts of interest: none.

IRB Information: This study was approved by the IRB at the Affiliated Hospital of

North Sichuan Medical College(IRB 2019ER(R)025 ), Contact: IRB specialist;

Jiemei Huang, Phone: 86-0817-2262124囚and written informed consent had been

obtained from all subjects participating in the trial. This study was registered prior to

patient enrollment at the Chinese Clinical Trial Registry(Principal investigator:

Fangjun Wang, Date of registration: February 3 2016), Registry

URL:http://www.chictr.org.cn/; Registration number: ChiCTR1900021254.

Presentation: none.

Authors' contributions

FJ W obtained funding for the research. All authors have contributed to the design of the study. HC X, Q Y, $D X$ and $L W$ were involved in the study design, the experiments performance, the data collection. XP G wrote the manuscript and reviewed and revised by FJ W and DX. All authors have edited, reviewed and approved the final version.

Author details

the Department of Anaesthesiology, Affiliated Hospital, North Sichuan Medical College, Nanchong, China

\section{References}

1. Lee JH, Kam EH, Kim SY, Cheon SY, Kim EJ, Chung S, Jeong JH, Koo BN. Erythropoietin Attenuates Postoperative Cognitive Dysfunction by Shifting Macrophage Activation toward the M2 Phenotype. Front Pharmacol.2017; 8:839. doi: 10.3389/fphar.2017.00839. eCollection 2017.

2. Needham MJ, Webb CE, Bryden DC. Postoperative cognitive dysfunction and dementia: what we need to know and do. Br J Anaesth.2017; 119(suppl_1):i115-i125. doi: 10.1093/bja/aex354. 
3. Plas M, Rotteveel E, Izaks GJ, Spikman JM, van der Wal-Huisman H, van Etten B, Absalom AR, Mourits MJE, de Bock GH, van Leeuwen BL. Cognitive decline after major oncological surgery in the elderly. Eur J Cancer. 2017; 86:394-402. doi: 10.1016/j.ejca.2017.09.024.

4. Nicholas Davis, Melissa Lee, Albert Y. Lin, Lisa Lynch, Matthew Monteleone, Louise Falzon, Nighat Ispahany, Susan Lei. Post-operative cognitive function following general versus regional anesthesia, a systematic review. J Neurosurg Anesthesiol. 2014; 26(4): 369-376. doi:

10.1097/ANA.0000000000000120.

5. Geng YJ, Wu QH, Zhang RQ. Effect of propofol, sevoflurane, and isoflurane on postoperative cognitive dysfunctionfollowing laparoscopic cholecystectomy in elderly patients: A randomized controlled trial. J Clin Anesth. 2017; 38:165-171. doi: 10.1016/j.jclinane. 2017.02.007.

6. Ekmekci P, Erkan G, Yilmaz H, Kazbek BK, Koksoy UC, Doganay G, Tüzüner F. Effect of Different Sedation Regimes onCognitiveFunctions in Colonoscopy. Euroasian J Hepato-Gastroenterol. 2017; 7(2):158-162. doi: 10.5005/jp-journals-10018-1239

7. Turgut N, Turkmen A, Ali A, Altan A. Remifentanil-propofol vs dexmedetomidine-propofol-- anesthesia for supratentorial craniotomy. Middle East J Anaesthesiol. 2009; 20(1):63-70.

8. Kim HC, Park HP, Lee J, Jeong MH, Lee KH. Sevoflurane vs. propofol in post-operative catheter-related bladder discomfort: a prospective randomized study. Acta Anaesthesiol Scand. 2017; 61(7):773-780. doi: $10.1111 /$ aas.12922.

9. Kim SY, Kim JM, Lee JH, Song BM, Koo BN. Efficacy of intraoperative dexmedetomidine infusion on emergence agitation and quality of recovery after nasal surgery. Br J Anaesth. 2013; 111(2):222-8. doi: $10.1093 / \mathrm{bja} /$ aet056.

10. Kerson AG, DeMaria R, Mauer E, Joyce C, Gerber LM, Greenwald BM, Silver G, Traube C. Validity of the Richmond Agitation-Sedation Scale (RASS) in critically ill children. J Intensive Care. 2016;4:65. eCollection 2016. doi: 10.1186/s40560-016-0189-5

11. Sayed Morteza Heidari, Parisa Loghmani. Assessment of the effects of ketamine-fentanyl combination versus propofol-remifentanil combination for sedation during endoscopic retrograde cholangiopancreatography. J Res Med Sci. 2014; 19(9): 860-6.

12. Li Y, He R, Chen S, Qu Y. Effect of dexmedetomidine on early postoperative cognitive dysfunction and peri-operative inflammation in elderly patients undergoing laparoscopic cholecystectomy. Exp Ther Med. 2015; 10 (5):1635-42. doi: 10.3892/etm.2015.2726

13. Monk TG, Price CC. Postoperative cognitive disorders. Curr Opin Crit Care. 2011; 17(4): 376-81. doi: 10.1097/MCC.0b013e328348bece.

14. Silbert BS, Evered LA, Scott DA. Incidence of postoperative cognitive dysfunction after general or spinal anaesthesia for extracorporeal shock wave lithotripsy. Br J Anaesth. 2014;113(5):784-91. doi: 10.1093/bja/aeu163.

15. Ologunde R, Ma D. Do inhalational anesthetics cause cognitive dysfunction? Acta Anaesthesiol Taiwan. 2011; 49:149-53. DOIख10.1016/j.aat.2011.11.001 
16. Culley DJ, Flaherty D, Fahey MC, Rudolph JL, Javedan H, Huang CC, Wright J, Bader AM, Hyman BT, Blacker D, Crosby G. Poor Performance on a Preoperative Cognitive Screening Test Predicts Postoperative Complications in Older Orthopedic Surgical Patients. Anesthesiology. 2017; 127(5): 765-74. doi: 10.1097/ALN.0000000000001859.

17. Wang FJ, Wang GF, Cai R, et al. Effects of remifentanil compound propofol and sevoflurane on cognitive and memory function in elderly patients. Chin J Gerontol. 2011;31(10):1894-6.

18. Zywiel MG, Prabhu A, Perruccio AV, Gandhi R. The influence of anesthesia and pain management on cognitive dysfunction after joint arthroplasty: a systematic review. Clin Orthop Relat Res. 2014; 472(5):1453-66. doi: 10.1007/s11999-013-3363-2.

19. İlvan $G$, Özköse $H Z$. The effect of total intravenous anesthesia on the postoperative cognitive functions of young and elderly patients after lumbar disk surgery. Turk J Med Sci. 2015;45(1): 1916.doi: 10.3906/sag-1311-29.

20. Wang Y, Sands LP, Vaurio L, Mullen EA, Leung JM. The effects of postoperative pain and its management on postoperative cognitive dysfunction. Am J Geriatr Psychiatry. 2007; 15(1):50-9. doi: 10.1097/01.jgp.0000229792.31009.

21. Kunimatsu T, Misaki T, Hirose N, Tsuboi E, Takahashi I, Ohki H, Oi Y, Matsumoto M, Tanaka H. Postoperative mental disorder following prolonged oral surgery. J Oral Sci. 2004; 46(2):71-4. doi: 10.2334/josnusd.46.71.

22. Magni G, Baisi F, La Rosa I, Imperiale C, Fabbrini V, Pennacchiotti ML, Rosa G. No difference in emergence time and early cognitive function between sevoflurane-fentanyl and propofolremifentanil in patients undergoing craniotomy for supratentorial intracranial surgery. J Neurosurg Anesthesiol 2005; 17: 134-8. doi:10.1097/01.ana.0000167447.33969.16.

23. Zhang D, Nie A. Assessment of different anesthesia depth under total intravenous anesthesia on postoperative cognitive function in laparoscopic patients. J Res Med Sci. 2016;21:73. eCollection 2016.doi: 10.4103/1735-1995.189679.

24. Poorzamany Nejat Kermany M, Dahi M, Yamini Sharif R, Radpay B. Comparison of the Effects of Dexmedetomidine and Remifentanil on Cognition State After Cataract Surgery. Anesth Pain Med. 2016; 6(3):e33448. doi: 10.5812/aapm.33448.

25. Tan JA, Ho KM. Use of dexmedetomidine as a sedative and analgesic agent in critically ill adult patients: a meta-analysis. Intensive Care Med. 2010; 36(6):926-39. doi: 10.1007/ s00134-010-1877-6.

26. Lu J, Chen G, Zhou H, Zhou Q, Zhu Z, Wu C. Effect of parecoxib sodium pretreatment combined with dexmedetomidine on early postoperative cognitive dysfunction in elderly patients after shoulder arthroscopy: A randomized double blinded controlled trial. J Clin Anesth. 2017; 41:30-4. doi: 10.1016/j.jclinane.2017.06.004

27. Li Y, He R, Chen S, Qu Y. Effect of dexmedetomidine on early postoperative cognitive dysfunction and peri-operative inflammation in elderly patients undergoing laparoscopic cholecystectomy. Exp Ther Med. 2015; 10(5):1635-42. doi: 10.3892/etm.2015.2726 
28. Kim HJ, Kim DK, Kim HY, et al. Risk factors of emergence agitation in adults undergoing general anesthesia for nasal surgery. Clin Exp Otorhinolaryngol. 2015; 8:46-51. doi:10.3342/ceo.2015.8.1.46

29. Yu D, Chai W, Sun X, et al. Emergence agitation in adults: risk factors in 2,000 patients. Can J Anaesth. 2010;57:843-8. doi囚10.1007/s12630-010-9338-9.

30. Munk L, Andersen G, Moller AM. Post-anaesthetic emergence delirium in adults: incidence, predictors and consequences. Acta Anaesthesiol Scand. 2016; 60:1059-66.doi: 10.1111/aas.12717.

31. Kwon Y, Jang JS, Hwang SM, Lee JJ, Tark H. Intraoperative administration of dexmedetomidine reduced the postoperative catheter-relatedbladder discomfort and pain in patients undergoing lumbar microdiscectomy. J Anesth. 2018; 32(1):41-7. doi: 10.1007/s00540-017-2425-0.

32. Akça B, Aydoğan-Eren E, Canbay Ö, Karagöz AH, Üzümcügil F, Ankay-Yilbaş A, Çelebi N. Comparison of efficacy of prophylactic ketamine and dexmedetomidine on postoperative bladder catheter-related discomfort. Saudi Med J. 2016;37(1):55-9. doi: 10.15537/smj. 2016.1.14122.

33. Kim HC, Lee YH, Jeon YT, Hwang JW, Lim YJ, Park JE, Park HP. The effect of intraoperative dexmedetomidine on postoperative catheter-related bladderdiscomfort in patients undergoing transurethral bladder tumour resection: A double-blind randomised study. Eur J Anaesthesiol. 2015;32(9):596-601. doi: 10.1097/EJA.0000000000000196.

34. Ingrid Rundshagen. Postoperative Cognitive Dysfunction. Dtsch Arztebl Int. 2014; 111(8): 119-25. doi: 10.3238/arztebl.2014.0119.

\section{Tables}

The Patient characteristics are shown intable 1. Patient characteristics were similar between the two groups, (Table 1).

Table 1 Demographic data.

\begin{tabular}{ccccc}
\hline Patient characteristics & $\begin{array}{c}\text { PR group } \\
n=60\end{array}$ & $\begin{array}{c}\text { PRD group } \\
n=60\end{array}$ & $F / X^{2}$ values & $P$ values \\
\hline Sex凸male / female & $35 / 25$ & $33 / 27$ & 4 & 0.2615 \\
level of education & $27 / 33$ & $29 / 31$ & 2 & 0.1573 \\
(illiterate / Primary school literacy) & & & 0.125 \\
Age(y) & $66.7 \pm 4.1$ & $65.6 \pm 3.4$ & 2.387 & 0.496 \\
Weight(kg) & $56.5 \pm 5.4$ & $55.8 \pm 5.9$ & 0.465 & 0.1573 \\
ASA(I/II) & $20 / 40$ & $18 / 42$ & 2 & 2 \\
\hline
\end{tabular}

Values are mean \pm SD, number of patients. ASA: American Society of Anesthesiologists; PR: Propofol-remifentanil; PRD: Propofol-remifentanil and dexmedetomidine.

The clinical characteristics are shown intable 2.The duration of surgery, time to spontaneous respiration and the length of stay in the PACU were similar in two groups. The dosage of propofol or remifentanil was significantly higher in PRD group compared with PR group $P<0.001 \square$. The time to recovery and tracheal extubation time were delayed greater in group PRD compared with group $\operatorname{PR}(P<0.001)$.

Table 2 Clinical characteristics in two groups 


\begin{tabular}{lcccc}
\hline Clinical characteristics & $\begin{array}{c}\text { PR group } \\
n=60\end{array}$ & $\begin{array}{c}\text { PRD group } \\
n=60\end{array}$ & $F$ values & $P$ values \\
\hline duration of surgery $\llbracket$ minute $\square$ & $93.4 \pm 10.9$ & $94.1 \pm 10.9$ & 0.124 & 0.725 \\
dosage of propofol $\square$ milligram $\square$ & $517.0 \pm 75.8$ & $335.8 \pm 40.8^{*}$ & 265.928 & 0.000 \\
dosage of remifentanil $\square$ microgram $\square$ & $486.0 \pm 53.2$ & $439.4 \pm 32.7^{*}$ & 33.407 & 0.000 \\
time to spontaneous respiration(minute) & $16.4 \pm 2.2$ & $17.1 \pm 2.8$ & 2.375 & 0.126 \\
time to recovery (minute) & $20.0 \pm 2.4$ & $24.5 \pm 3.6^{*}$ & 64.195 & 0.000 \\
tracheal extubation time (minute) & $21.2 \pm 2.7$ & $25.4 \pm 3.6^{*}$ & 53.371 & 0.000 \\
& & & & \\
PACU stay time(minute) & $66.2 \pm 5.2$ & $67.9 \pm 6.5$ & 2.544 & 0.113 \\
\hline
\end{tabular}

Values are mean \pm SD. PR: Propofol-remifentanil; PRD: Propofol-remifentanil and dexmedetomidine; PACU: postanesthesia care unit. ${ }^{*} p<0.001$ vs. PR group

The Richmond AgitationSedation scores are shown in table 3.The RASS scores in the PRD group was significantly lower than in PR group at $t_{1}, t_{2}, t_{3}(P<0.001)$.The incidence of EA in the PRD group was significantly lower than in PR group at $\mathrm{t} 1(10.0 \%[6 / 54]$ vs $40.0 \%[24 / 36])$, $\mathrm{t} 2(3.3 \%$ [2/58] vs $40.0 \%[24 / 36])$, t3(0.0\%[0/60] vs $23.3 \%[14 / 46])$, (Table 3$)$.

Table 3 The Richmond AgitationSedation scores at 10, 20, 30 and 60 minutes after extubation in two groups.

\begin{tabular}{ccccccccc}
\hline Time & Group & $\square 1$ & 0 & 1 & 2 & 3 & $X^{2}$ & P values \\
\hline $\mathrm{t}_{1}$ & $\mathrm{PR}$ & 0 & 10 & 26 & 14 & 10 & 42.329 & $0.000^{*}$ \\
& $\mathrm{PRD}$ & 12 & 25 & 17 & 6 & 0 & & \\
$\mathrm{t}_{2}$ & $\mathrm{PR}$ & 0 & 17 & 19 & 16 & 8 & 54.262 & $0.000^{*}$ \\
& $\mathrm{PRD}$ & 21 & 23 & 14 & 2 & 0 & & \\
$\mathrm{t}_{3}$ & $\mathrm{PR}$ & 5 & 13 & 28 & 14 & 0 & 48.415 & $0.000^{*}$ \\
& $\mathrm{PRD}$ & 14 & 38 & 8 & 0 & 0 & & \\
$\mathrm{t}_{4}$ & $\mathrm{PR}$ & 7 & 36 & 17 & 0 & 0 & 2.930 & 0.231 \\
& $\mathrm{PRD}$ & 7 & 42 & 9 & 0 & 0 & & \\
\hline
\end{tabular}

Number of patients. PR: Propofol-remifentanil; PRD: Propofol-remifentanil and dexmedetomidine. $t_{1}: 10$ minutes after extubation, $t_{2}: 20$ minutes after extubation, $\mathrm{t}_{3}: 30$ minutes after extubation, $\mathrm{t}_{4}: 60$ minutes after extubation. ${ }^{*} P[0.001 \mathrm{vs}$. group PR

The Mini Mental State Examination scores are shown in table 4. The MMSE scores were lower at $\mathrm{T}_{1}$ and $\mathrm{T}_{2}$ compared to $\mathrm{T}_{0}$ in two groups $(P<0.001)$. The MMSE scores were similar between the two groups at $\mathrm{T}_{0}, \mathrm{~T}_{1}, \mathrm{~T}_{2}, \mathrm{~T}_{3}, \mathrm{~T}_{4}$ and $\mathrm{T}_{5}(P>0.05)$.

Table 4 The Mini Mental State Examination scores at $\mathrm{T}_{0}, \mathrm{~T}_{1}, \mathrm{~T}_{2}, \mathrm{~T}_{3}, \mathrm{~T}_{4}$ and $\mathrm{T}_{5}$ in two groups.

\begin{tabular}{ccccc}
\hline & PR & PRD & $F$ values & $P$ values \\
\hline $\mathrm{T}_{0}$ & $25.4 \pm 2.2$ & $25.5 \pm 2.5$ & 0.431 & 0.700 \\
$\mathrm{~T}_{1}$ & $20.7 \pm 2.1^{*}$ & $21.3 \pm 2.5^{*}$ & 0.423 & 0.183 \\
$\mathrm{~T}_{2}$ & $22.8 \pm 2.0^{*}$ & $23.3 \pm 2.0^{*}$ & 0.367 & 0.223 \\
$\mathrm{~T}_{3}$ & $25.0 \pm 2.2$ & $25.2 \pm 2.6$ & 0.432 & 0.644 \\
$\mathrm{~T}_{4}$ & $25.1 \pm 2.2$ & $25.2 \pm 2.4$ & 0.421 & 0.664 \\
$\mathrm{~T}_{5}$ & $25.3 \pm 2.2$ & $25.4 \pm 2.5$ & 0.429 & 0.756 \\
$F$ values & 129.34 & 105.55 & - & - \\
$P$ values & 0.000 & 0.000 & - & - \\
\hline
\end{tabular}

Values are mean \pm SD. PR: Propofol-remifentanil; PRD: Propofol-remifentanil and dexmedetomidine; $\mathrm{T}_{0}$ : before the induction of anesthesia, $\mathrm{T}_{1}: 3 \mathrm{~h}$ after surgery, $\mathrm{T}_{2}: 6 \mathrm{~h}$ after surgery, $\mathrm{T}_{3}: 24 \mathrm{~h}$ after surgery. $\mathrm{T}_{4}: 48 \mathrm{~h}$ after surgery. $\mathrm{T}_{5}: 72 \mathrm{~h}$ after surgery. ${ }^{*} p<0.001$ vs. $\mathrm{T}_{0}$ 
The Zung Self-Rating Depression Scale scoresare shown in table 5. The ZSDS scores in PRD group were lower compared to PR group at $\mathrm{T}_{1}$ and $\mathrm{T}_{2}(P<0.001)$, and the ZSDS scores were similar between the two groups at $\mathrm{T}_{0}, \mathrm{~T}_{3}, \mathrm{~T}_{4}$ and $\mathrm{T}_{5}$. The ZSDS scores were higher at $\mathrm{T}_{1}$ and $\mathrm{T}_{2}$ compared to $\mathrm{T}_{0}$ in PR group $(P<0.001)$, and there were no differences in ZSDS scores at $\mathrm{T}_{0}, \mathrm{~T}_{1}, \mathrm{~T}_{2}, \mathrm{~T}_{3}, \mathrm{~T}_{4}$ and $\mathrm{T}_{5}$ in PRD groups $(P=0.359)$.

Table 5 The Zung Self-Rating Depression Scale scores at $\mathrm{T}_{0}, \mathrm{~T}_{1}, \mathrm{~T}_{2}, \mathrm{~T}_{3}, \mathrm{~T}_{4}$ and $\mathrm{T}_{5}$ in two groups.

\begin{tabular}{|c|c|c|c|c|c|c|c|c|c|}
\hline Group & $\mathrm{n}$ & $\mathrm{T}_{0}$ & $\mathrm{~T}_{1}$ & $\mathrm{~T}_{2}$ & $\mathrm{~T}_{3}$ & $\mathrm{~T}_{4}$ & $\mathrm{~T}_{5}$ & $F$ values & $P$ values \\
\hline PR & 60 & $43.2 \pm 2.2$ & $48.1 \pm 2.5^{*}$ & $46.2 \pm 2.4^{*}$ & $43.6 \pm 1.6$ & $43.2 \pm 1.7$ & $43.3 \pm 1.9$ & 69.06 & 0.000 \\
\hline PRD & 60 & $42.8 \pm 2.4$ & $43.4 \pm 2.2^{\#}$ & $43.2 \pm 1.7^{\#}$ & $42.9 \pm 2.0$ & $42.7 \pm 2.2$ & $42.8 \pm 1.70$ & 1.35 & 0.248 \\
\hline \multicolumn{2}{|c|}{$F$ values } & 0.419 & 0.434 & 0.379 & 0.329 & 0.357 & 0.333 & - & - \\
\hline \multicolumn{2}{|c|}{$P$ values } & 0.362 & 0.000 & 0.000 & 0.028 & 0.138 & 0.136 & - & - \\
\hline
\end{tabular}

Values are mean \pm SD. PR: Propofol-remifentanil; PRD: Propofol-remifentanil and dexmedetomidine. $\mathrm{T}_{0}$ : before the induction of anesthesia, $\mathrm{T}_{1}: 3 \mathrm{~h}$ after surgery, $\mathrm{T}_{2}: 6 \mathrm{~h}$ after surgery, $\mathrm{T}_{3}: 24 \mathrm{~h}$ after surgery. $\mathrm{T}_{4}: 48 \mathrm{~h}$ after surgery. $\mathrm{T}_{5}: 72 \mathrm{~h}$ after surgery. ${ }^{*} p<0.001 \mathrm{vs}$. $\mathrm{T}_{0},{ }^{\#} p<0.005$ vs.PR group.

The State-Trait Anxiety Inventoryscores are shown in table 6. The STAI scores were higher at $\mathrm{T}_{1}$ and $\mathrm{T}_{2}$ compared to $\mathrm{T}_{0}$ in PR group, and the STAI scores were higher at $\mathrm{T}_{1}$ compared to $\mathrm{T}_{0}$ in PRD group. The STAI scores at $\mathrm{T}_{1}$ and $\mathrm{T}_{2}$ were lower in PRD group compared to PR group $(P<0.005)$.

Table 6 The State-Trait Anxiety Inventoryscores at $\mathrm{T}_{0}, \mathrm{~T}_{1}, \mathrm{~T}_{2}, \mathrm{~T}_{3}, \mathrm{~T}_{4}$ and $\mathrm{T}_{5}$ in two groups.

\begin{tabular}{|c|c|c|c|c|c|c|c|c|c|c|}
\hline Index & Group & $\mathrm{n}$ & $\mathrm{T}_{0}$ & $\mathrm{~T}_{1}$ & $\mathrm{~T}_{2}$ & $\mathrm{~T}_{3}$ & $\mathrm{~T}_{4}$ & $\mathrm{~T}_{5}$ & $F$ values & Pvalues \\
\hline \multirow[t]{4}{*}{ S-AI } & $\mathrm{PR}$ & 60 & $38.9 \pm 3.4$ & $48.6 \pm 3.6^{*}$ & $45.3 \pm 3.7 *$ & $39.0 \pm 3.0$ & $39.1 \pm 3.1$ & $39.1 \pm 3.4$ & 171.05 & 0.000 \\
\hline & PRD & 60 & $39.5 \pm 2.6$ & $45.5 \pm 2.5^{* \#}$ & $39.9 \pm 2.3^{\#}$ & $39.9 \pm 2.3$ & $39.5 \pm 2.3$ & $39.6 \pm 2.0$ & 36.30 & 0.000 \\
\hline & \multicolumn{2}{|c|}{$F$ values } & 0.554 & 0.561 & 0.565 & 0.490 & 0.504 & 0.507 & - & - \\
\hline & \multicolumn{2}{|c|}{$P$ values } & 0.294 & 0.000 & 0.000 & 0.079 & 0.509 & 0.266 & - & - \\
\hline \multirow[t]{4}{*}{$\mathrm{T}-\mathrm{AI}$} & PR & 60 & $40.4 \pm 2.9$ & $46.9 \pm 3.1 *$ & $45.9 \pm 2.9 *$ & $40.7 \pm 2.5$ & $40.5 \pm 2.5$ & $40.7 \pm 2.5$ & 74.79 & 0.000 \\
\hline & PRD & 60 & $41.1 \pm 2.2$ & $45.1 \pm 3.1^{* \#}$ & $41.4 \pm 1.9^{\#}$ & $40.8 \pm 2.8$ & $40.6 \pm 2.2$ & $40.7 \pm 2.4$ & 45.99 & 0.000 \\
\hline & \multicolumn{2}{|c|}{$F$ values } & 0.468 & 0.565 & 0.449 & 0.490 & 0.436 & 0.447 & - & - \\
\hline & \multicolumn{2}{|c|}{$P$ values } & 0.179 & 0.002 & 0.000 & 0.812 & 0.789 & 1.000 & - & - \\
\hline
\end{tabular}

Values are mean \pm SD. PR: Propofol-remifentanil; PRD: Propofol-remifentanil and dexmedetomidine. S-AI: State Anxiety Inventory; T-AI: State-Trait Anxiety Inventory. $\mathrm{T}_{0}$ : before the induction of anesthesia, $\mathrm{T}_{1}: 3$ hafter surgery, $\mathrm{T}_{2}: 6 \mathrm{~h}$ after surgery, $\mathrm{T}_{3}: 24 \mathrm{~h}$ after surgery. $\mathrm{T}_{4}: 48 \mathrm{hafter}$ surgery. $\mathrm{T}_{5}: 72 \mathrm{~h}$ after surgery. ${ }^{*} p<0.001 \mathrm{vs} . \mathrm{T}_{0},{ }^{\#} p<0.005$ vs.PR group.

The recalled arabic numbers are shown in table 7. The recalled arabic numbers were lower at $\mathrm{T}_{1}$ and $\mathrm{T}_{2}$ in $\mathrm{PR}$ group and at $\mathrm{T}_{1}$ in $\mathrm{PRD}$ group compared to $\mathrm{T}_{0}(P<0.001)$. The recalled arabic numbers were higher at $\mathrm{T}_{2}$ in PRD group compared to $\mathrm{PR}$ group $(P<0.001)$.

Table 7 The recalled arabic numbers at $\mathrm{T}_{0}, \mathrm{~T}_{1}, \mathrm{~T}_{2}, \mathrm{~T}_{3}, \mathrm{~T}_{4}$, and $\mathrm{T}_{5}$ in two groups. 


\begin{tabular}{c|c|c|c|c|c|c|c|c|c|}
\hline Group & $\mathrm{n}$ & $\mathrm{T}_{0}$ & $\mathrm{~T}_{1}$ & $\mathrm{~T}_{2}$ & $\mathrm{~T}_{3}$ & $\mathrm{~T}_{4}$ & $\mathrm{~T}_{5}$ & $F$ values & $P$ values \\
\hline $\mathrm{PR}$ & 60 & $4.4 \pm 0.6$ & $2.7 \pm 0.7^{*}$ & $3.1 \pm 0.7^{*}$ & $4.2 \pm 0.7$ & $4.3 \pm 0.6$ & $4.3 \pm 0.7$ & 61.79 & 0.000 \\
\hline PRD & 60 & $4.3 \pm 0.7$ & $2.6 \pm 0.8^{*}$ & $4.1 \pm 0.7^{\#}$ & $4.3 \pm 0.7$ & $4.2 \pm 0.6$ & $4.3 \pm 0.7$ & 55.09 & 0.000 \\
\hline$F$ values & & 0.118 & 0.134 & 0.126 & 0.127 & 0.114 & 0.122 & - & - \\
\hline$P$ values & & 0.573 & 0.323 & 0.000 & 0.694 & 0.465 & 1.000 & - & - \\
\hline
\end{tabular}

Values are mean \pm SD. PR: Propofol-remifentanil; PRD: Propofol-remifentanil and dexmedetomidine. S-AI: State Anxiety Inventory; T-AI: State-Trait Anxiety Inventory. $T_{0}$ : before the induction of anesthesia, $\mathrm{T}_{1}: 3 \mathrm{~h}$ after surgery, $\mathrm{T}_{2}: 6 \mathrm{~h}$ after surgery, $\mathrm{T}_{3}: 24 \mathrm{~h}$ after surgery, $\mathrm{T}_{4}: 48 \mathrm{~h}$ after surgery. $\mathrm{T}_{5}: 72 \mathrm{~h}$ after surgery. ${ }^{*} p<0.001 \mathrm{vss}_{0},{ }^{*} p<0.001 \mathrm{vs} . \mathrm{PR}$ group.

\section{Figures}

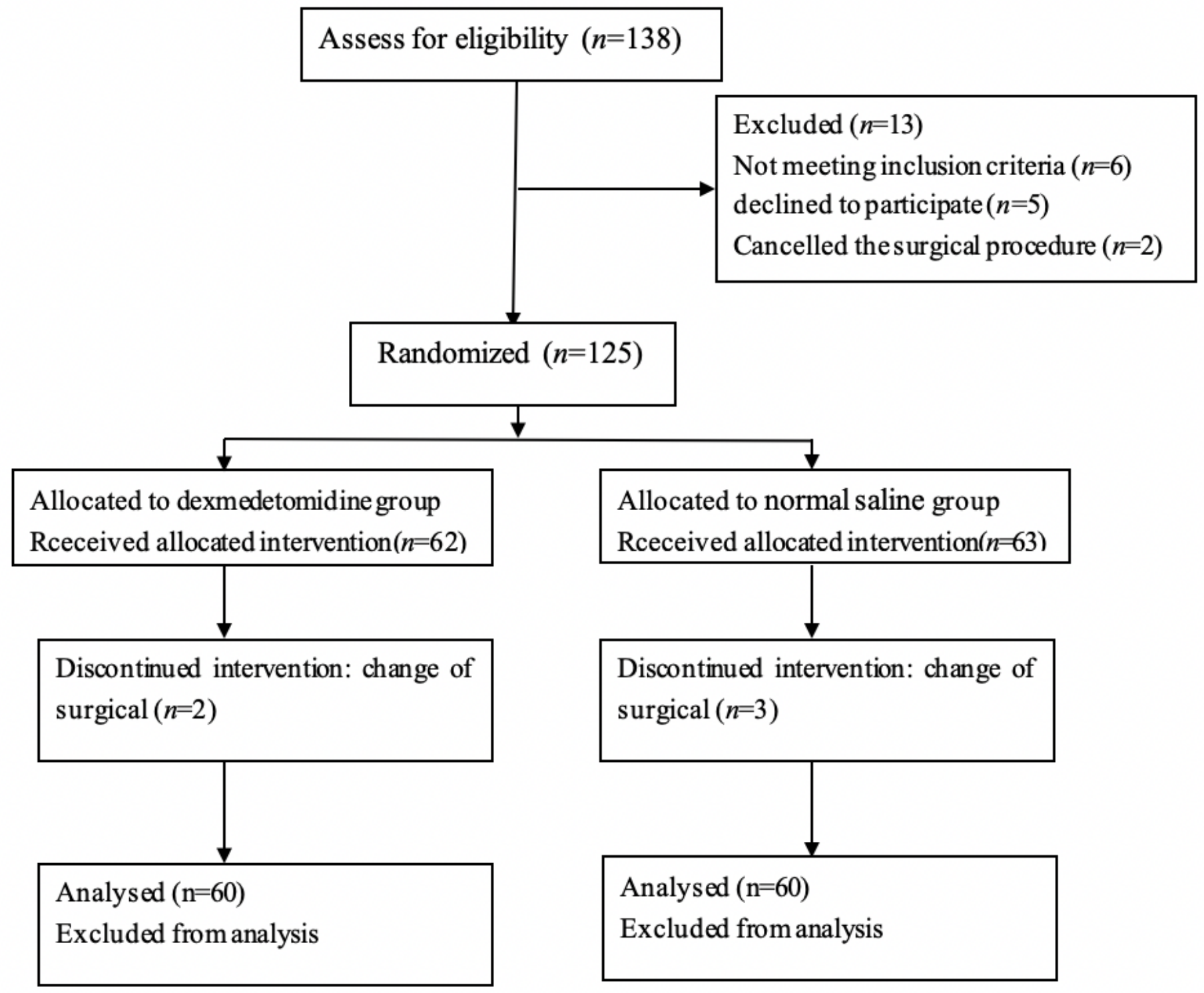

Figure 1 
Study flow diagram. One hundred and thirty-four patients were screened for eligibility, six patients with hypertension were excluded, five patients declined to participate and two patients were Cancelled the surgical procedure. 125 patients were subsequently allocated to two groups. During operation, five patients were change of surgical. A total of one hundred and twenty patients completed the study.

\section{Supplementary Files}

This is a list of supplementary files associated with this preprint. Click to download.

- CONSORT2010Checklist.doc

- renamed60dc9.xlsx 